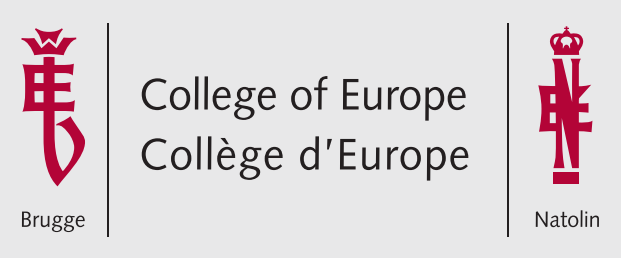

www.cole urope.e u

\title{
Permanent Structured Cooperation in Defence: Building Effective European Armed Forces
}

Bruges Political

Research Papers 
European Political and Administrative Studies Études Politiques et Administratives

Bruges Political Research Papers / Cahiers de recherche politique de Bruges

No 15 / September 2010

Permanent Structured Cooperation in Defence: Building Effective European Armed Forces

by Sven Biscop and Jo Coelmont

(C) Sven Biscop and Jo Coelmont, 2010

European Political and Administrative Studies/

Études Politiques et Administratives

Dijver 11, B-8000 Brugge, Belgium

www.coleurope.eu/pol 
About the authors

Professor Doctor Sven Biscop is Director of the Europe in the World programme at Egmont and Visiting Professor at the College of Europe (Bruges) and at Ghent University.

Brig-Gen. (R). Joe Coelmont is a Senior Associate Fellow in the Europe in the World programme at Egmont. He is the former Belgian Representative to the EUMC.

Address for Correspondence:

s.biscop@egmontinstitute.be - jo.coelmont@telenet.be

\section{Editorial Team}

Michele Chang, Camille Kelbel, Maylis Labayle, Alexandra Paul, Constance Poiré, Eviola Prifti, Adrien Sellez and Jörg Monar

Dijver 11, B-8000 Bruges, Belgium । Tel. +32 (0) 50477281 । Fax +32 (0) 50477280 । email michele.chang@ coleurope.eu I website www.coleurope.eu/pol

Views expressed in the Bruges Political Research Papers are solely those of the author(s) and do not necessarily reflect positions of either the series editors or the College of Europe.

If you would like to be added to the mailing list and be informed of new publications and department events, please email rina.balbaert@coleurope.eu. Or find us on Facebook, College of Europe Politics and Administration Department. 
Abstract:

Sven Biscop and Jo Coelmont outline a concrete proposal to implement Permanent Structured Cooperation, the new mechanism introduced by the Lisbon Treaty in the area of the Common Security and Defence Policy. Their proposal comprises three dimensions: real but realistic criteria; a permanent capability generation conference; and promotion of pooling and sharing. On such a basis, Permanent Structured Cooperation offers real added value to the EU and Member States alike 


\section{Introduction}

If the European Union is to be ready to share in the responsibility for global security and building a better world, as the European Security Strategy states, it is evident that the Common Security and Defence Policy (CSDP) must be strengthened: Europe still struggles to deploy more than $4 \%$ of its 1.8 million troops, and still the major capability shortfalls have not been addressed. Obviously, the existing mechanisms for capability development in the EU (as well as in NATO for that matter) have failed to generate significantly more deployable capabilities, and will probably never do so. If no action is taken, one cannot even hope for a standstill. Things will get worse, because of the economic crisis, which has already resulted in yet another series of budgetary cuts, and which will ensure continued budgetary pressure on all Member States. So the challenge is to provide the Union with more effective military capabilities notwithstanding the current budgetary hurdles.

CSDP needs a new stimulus. The Lisbon Treaty actually provides several, not in the least the appointment of a permanent President of the European Council and the strengthening of the position of the High Representative, which can be hoped to generate more strategy, coherence and proactive policies at the highest political level. The extended definition of the Petersberg Tasks and the adoption of the Solidarity Clause, allowing the use of CSDP within the territory of the Union, will help as well to set directions for future CSDP operations. Mutual defence is another important addition. That leaves the required capabilities, in which area the Treaty introduces a new mechanism: Permanent Structured Cooperation in Defence (PSCD).

Unfortunately, PSCD features high among the provisions of the Lisbon Treaty that many EU Member States seem to have forgotten that they subscribed to. Perhaps because it is 
so ambitious: by setting criteria for participation, for the first time participating Member States (pMS) would enter into binding commitments in the field of defence and allow an EU body, the European Defence Agency (EDA), to assess their performance. This high level of ambition was clear from the outset, when PSCD was first formulated in the Convention. It is true, the Convention's initial proposals had an exclusive flavour to them, as some sought to create a small avant-garde of those Member States spending the most on defence and launching the most sophisticated armaments programmes, with the others being relegated to a secondary role. Such a scheme would indeed have been divisive. However, from the moment of its incorporation in the Constitutional Treaty, the provisions of which were afterwards copied into the Lisbon Treaty, PSCD has been in the process of being rethought as an inclusive mechanism, aiming to incorporate as many Member States as possible. As EUoperations have shown, e.g. in Chad, the contributions of all Member States are indeed welcome and necessary.

Therefore, the challenge now is to configure PSCD in such a way that it strengthens CSDP without dividing the Union. Rather, PSCD ought to increase solidarity and convergence. No longer seeking to establish an exclusive and highly political vanguard signposting the way ahead, the aim now is to create a pragmatic process that is attractive to all Member States, output-oriented and cost-effective. 


\section{The Objective: More Capable, More Deployed}

The Protocol on PSCD annexed to the Lisbon Treaty sets out two objectives (Art. 1), one of which, i.e. to supply or contribute to a Battle Group, has already been achieved by most Member States. This leaves a single major objective: to proceed more intensively to develop defence capacities, which must of course be available and deployable, as Art. 2 (c) says. Thus PSCD should enable participating Member States (pMS) to increase at a quicker pace than at present their national level of ambition in terms of deployability and sustainability. In other words, pMS will be able to field more capabilities for the full range of operations in all frameworks in which they engage: CSDP, NATO, the UN, and others. In doing so, they will contribute to the achievement of the overall objectives for the Common Foreign and Security Policy (CFSP) and CSDP to which they have agreed in the Lisbon Treaty.

Through PSCD, pMS can step up their national contribution and/or, as stressed in Art. 1, participate in multinational forces, European equipment programmes and the activities of the EDA. The main problem of Europe's armed forces is fragmentation: limited defence budgets spent on a plethora of small-scale capabilities result in disproportionately high spending on "overhead" (and useless intra-European duplications) and, consequently, less spending on deployable capabilities and actual operations. To overcome this inefficiency, multinational cooperation is a must. Hence PSCD must be inclusive: the more pMS, the more synergies and effects of scale can be created. Thus, PSCD must reconcile inclusiveness and ambition, i.e. must translate Art. 2 of the Protocol into quantitative proportional criteria that allow all Member States to participate but that do entail a real commitment. 


\section{Criteria for Participation: Realistic but Real}

Art. 2 of the Protocol mentions five areas which now have to be operationalized by pMS:

- To agree on objectives for the level of investment in defence equipment;

- To "bring their defence apparatus into line with each other as far as possible", by harmonizing military needs, pooling, and, "where appropriate", specialization;

- To enhance their forces' availability, interoperability, flexibility and deployability, notably by setting "common objectives regarding the commitment of forces";

- To address the shortfalls identified by the Capability Development Mechanism (CDM), including through multinational approaches;

- To take part, "where appropriate", in equipment programmes in the context of the EDA.

When translating Art. 2 into concrete criteria, pMS must take into account that criteria for participation must be realistic, i.e. they must be within reach of the majority of Member States, and must stimulate them to tackle the obstacles to deployability and sustainability, notably by addressing the capability shortfalls identified in the Headline Goal process.

This has 3 implications: First, pMS cannot be expected to fulfil the criteria at the launching of PSCD: criteria must be fulfilled by an agreed deadline. Second, criteria that are 
unrealistic and cannot be expected to generate more deployable capabilities in a reasonable timeframe, e.g. defence expenditures representing $2 \%$ of GDP, should be avoided. This is especially true in times of economic crisis. Finally, PSCD must not just focus on the input, i.e. the level and manner of spending, but also on the desired output, i.e. on deployable capabilities. The obstacles and capability gaps are well-known, hence there is no need to concentrate on developing a new Headline Goal, which will simply result in a very similar document. Rather PSCD will be a way of achieving the existing HG2010 - which must indeed be considered a living document - in a reasonable timeframe. That is the desired output.

Taking these implications into account, the following criteria can be envisaged - these must be seen as one set, to be pursued simultaneously:

Criterion 1: The overall objective of PSCD is that pMS increase their deployability and sustainability by an agreed $\%$ by an agreed deadline, e.g. by $25 \%$ in 5 years and by $50 \%$ in 10 years, until they have reached an agreed target, e.g. 50\% deployability and 10\% sustainability (to the latter most Member States have already agreed in the context of NATO). Thus if PSCD is launched in 2010, a pMS which now has the ambition to always have 1000 troops in the field, should e.g. aim to continually field 1250 by 2015, and 1500 by 2020 . The objective could be detailed for each component, army, navy and air force, and might also be expressed as a \% of the total population of each pMS, as a measure of solidarity and burdensharing. How to achieve this (enhancing cost-effectiveness, pooling, specialization etc.) is at the discretion of each individual pMS, but the final objective is the same for all.

Criterion 2: In view of solidarity and burden-sharing, pMS should strive to harmonize their defence expenditures, particularly those pMS spending less than the EU average (in 2008, 1,63\% of GDP for the 26 Member States participating in the EDA). At the very least, 
pMS spending less should commit not to further decrease their defence expenditures, neither in real terms nor in \% of GDP.

Criterion 3: pMS should contribute fully to the programmes of the EDA, which is to be used as the forum to mount collective projects, notably to address the commonly identified strategic shortfalls. Obviously, pMS cannot take part in each and every EDA project; they will select specific programmes that fit with their expertise and force structure. But their share in the overall cost of all projects combined should reflect their respective GDP, in order to ensure fair burden-sharing between pMS.

Criterion 4: As an expression of the political solidarity that must underpin CSDP, pMS will participate in all CSDP operations requiring military assets (of the unanimous Council decision to launch which they are of course a part) with significant contributions, i.e. with military forces deployed in theatre and listed in the Statement of Requirements; the size and type are left to their own discretion.

\section{PSCD as a Permanent Capability Generation Conference}

Fulfilling these criteria will ensure that pMS have money to spend - the third criterion should help to ensure that they will spend it where it is most needed. Experience shows, however, that even repeated calls to reconsider and harmonize national defence planning in order to focus on the commonly identified capability shortfalls yield little results. Useful inspiration 
can be found in the method used to launch CSDP operations: a Force Generation Conference. ${ }^{1}$ Although such conferences can be difficult, as was the case for the Chad operation e.g., in the end they have always yielded result.

Within PSCD the EDA can organize a "Capability Generation Conference" aimed at remedying each commonly identified shortfall within a reasonable timeframe ${ }^{2}$ and functioning as a peer review of investment plans. This implies that pMS are willing:

- To revisit their national defence planning, without any taboos;

- To do away with national capability initiatives proven to be redundant;

- To pool assets and capabilities in order to generate savings;

- To contribute in function of their GDP to the programmes launched to fill the shortfalls, as per criterion 3;

- To actively contribute to negotiations for as long as it takes to achieve success.

This would indeed result in a permanent conference - but also in a permanently relevant EDA.

\footnotetext{
${ }^{1}$ Once the military assets and capabilities required for a specific upcoming CSDP operation are identified, Force Generation Conferences are organized among Troop Contributing Nations. This process goes on until the entire list of requirements has been met.

${ }^{2}$ In defence planning, the first significant results can reasonably be expected within 5 years, with cruising speed attained within 10 to 15 years. That fact should not be a cause for discouragement, but should rather stimulate all concerned not to postpone action any longer.
} 


\section{5. "End-to-End" Multinational Cooperation: Pooling}

The reality is that many pMS will not be able to meet the criteria and contribute significant capabilities if they maintain the same range of nationally organized capabilities that they possess today. Therefore identifying the opportunities for multinational cooperation is an essential instrument to achieve PSCD, allowing pMS to contribute relevant capabilities in a cost-effective way.

The EDA will have the bird's eye view: based on the information which in the context of the Capability Development Plan (CDP) pMS already provide (and must continually update) about their plans and programmes, and in combination with the progressive results of the Capability Generation Conference, it will be able to identify opportunities for cooperation.

Multinational cooperation does not imply that all pMS in PSCD cooperate in all capability areas. Rather within the single PSCD a set of overlapping clusters will emerge, with e.g. pMS 1, 2 and 3 cooperating in area $\mathrm{X}$ and pMS 2, 3, 4 and 5 cooperating in area $\mathrm{Y}$. This cooperation can take various forms, from joint procurement or development projects but with the aim of afterwards equipping national formations, to pooling, i.e. the creation of permanent multinational formations. The latter type of "end-to-end" cooperation will be the most effective in terms of enhancing cost effectiveness, but the beauty of PSCD is its flexibility: it functions as a wedding agency for those pMS seeking cooperation - which should stop flirting with the concept and implement it - but without obliging pMS that prefer to contribute nationally to engage in it.

The model for pooling can be provided by EATC: deployable national assets, in this case transport aircraft, remain clearly identifiable and manned by national personnel, but are 
co-located on one base, where all support functions are multinationalized, as are the command \& control arrangements. Thus pooling can still offer great flexibility: each pMS in EATC has to guarantee that its personnel in the support and in the command \& control structures will be available whenever a pMS deploys its aircraft - but no pMS is obliged to deploy its own actual aircraft each and every time another pMS deploys its aircraft for a specific operation.

The same model can be applied to fighter wings or army divisions. E.g. by anchoring the Belgian median brigade more firmly in the Eurocorps, cost effectiveness can be enhanced because each individual pMS no longer has to nationally organize all support functions required at division and corps level. pMS can focus defence spending on the line battalions, which remain entirely national, and on a more limited range of support functions, as some support functions can be abolished at the national level, either in favour of participation in a multinational Eurocorps structure or because another Eurocorps pMS will assume responsibility in that particular area.

Pooling can thus be an important instrument to achieve the objectives of PSCD, either by deepening integration in relevant existing multinational formations (but without aspiring to pull all existing frameworks into PSCD), or by new initiatives. Today, most multinational formations have limited permanent elements and except for FHQs are rarely if ever the framework in which troops are deployed. In some cases, pMS could base cooperation on successful common experience in providing a Battle Group, using that as a basis to build a larger-scale and more permanent multinational formation. In a way, the Battle Groups predict the pattern of cooperation, as in that context the usual suspects for cooperation have already found each other. PSCD can thus provide the link between the many existing bottom-up initiatives and the need for more top-down steering. 
Obviously, pooling is easier when pMS use the same equipment, hence smaller pMS especially will inevitably have to take into account with whom they want to cooperate as a major factor in procurement decisions. For pooling to increase cost-effectiveness, national structures and bases must naturally be pooled and thus in some instances cut.

\section{The Crucial Role of the EDA}

Art. 3 of the Protocol gives a crucial role to the EDA, which "shall contribute to the regular assessment of pMS' contributions [...] and shall report thereon at least once a year". A binding commitment needs a body overseeing its implementation. Art. 46 (4) TEU even provides for the possibility of suspension from PSCD if a pMS no longer fulfils the criteria. Those decisions will be taken by the pMS, on the basis of the data collection and assessment by the EDA.

Enabling the EDA to fulfil this task has a number of implications, translated into the following proposals:

- Obviously, pMS must continue to show full transparency to the EDA about all aspects of their defence effort. The EDA must be able to freely enter into contact with all relevant national authorities of pMS;

- The EDA will have to organize itself for its assessment role. If additional staff or funds are required, pMS should provide these, according to GDP. Contribution of national personnel to the relevant EDA body would ensure that the views of all pMS are represented in each assessment; 
- In view of democratic accountability and as a measure of peer pressure, the results of the assessment process should as far as possible be made public. This could be part of an EDA Yearbook on CSDP, a comprehensive report on CSDP policies and current operations, but focussing in particular on capability development and the contribution of each pMS.

A real assessment of capabilities concerns not just the figures, but performance in the field. In addition to the role of the EDA and on a voluntary basis, pMS could also agree to exercises and manoeuvres and "tactical evaluation" by the EU Military Staff, which could in time lead to a process of certification.

\section{Common Funding}

The decision to launch a CSDP operation is taken by the Council acting unanimously and thus each time reflects the broadest political solidarity. However, the current rules governing the sharing among Member States of expenditures arising from the military implications of such an operation, the Athena mechanism, do not reflect a similar solidarity. For military CSDP operations very few expenditures are eligible for common funding. The guiding principle is still "costs lie where they fall", meaning in practise that those Member States providing the required military forces and capabilities also have the honour to pay for about $90 \%$ of the total cost of a given operation. More solidarity in terms of funding would encourage more Member 
States to participate with even larger military contributions and ease the process of "Force Generation Conferences".

For CSDP operations, pMS could be encouraged to create in PSCD their own more equitable system of burden-sharing, based on common funding. A key to share the global common costs among pMS would be established (which could be similar to the one used at present by Member States for CSDP operations). Contributing capabilities mentioned in the Statement of Requirements would however count as a contribution in kind. pMS would thus be encouraged to invest in the "right" capabilities and to effectively deploy them.

\section{Launching and Governing PSCD}

The Treaty states that the Member States intending to participate notify the Council, which will launch PSCD by a Qualified Majority Vote (QMV) of all Member States, after consulting the High Representative (Art. 46 (2) TEU). Later admissions, and suspensions, will be decided upon by QMV of the pMS only. All other decisions will be taken by unanimity of the pMS.

In order to signal their commitment and ensure the necessary political impetus, it is proposed that pMS mark the creation of PSCD by a declaration at the level of the European Council. Only the Heads of State and Government can provide the high-level political impetus that will stimulate Foreign and Defence Ministers to take action. The annual report on PSCD by the EDA should be discussed at that level as well, for the European Council to 
define general guidelines. Within those guidelines pMS in the Foreign Affairs Council, chaired by the High Representative, can adopt the necessary decisions. Within the board of the EDA, pMS' Ministers of Defence should also meet regularly, e.g. twice yearly, in order to monitor progress and inform the Council and European Council prior to the discussion of the annual report. Within the EU Military Committee too and the working groups advising it, pMS can discuss PSCD.

pMS can thus make full use of all existing EU institutions to govern capability development in the context of PSCD. In order to ensure full coordination, non-pMS can always participate in all PSCD-related discussions, without voting rights. That will also ensure maximum information when deciding on operations, always by unanimity of all Member States.

\section{Conclusion: Real Added Value}

The added value of such PSCD is real, for the EU, NATO, national governments, and taxpayers alike.

Inclusiveness. PSCD is not to punish or exclude, but to encourage all to do more; the best PSCD is that at $27 .{ }^{3}$ Yes, the defence budgets of many individual Member States are relatively modest in scale, but together they represent tens of billions of euros - a chance to

\footnotetext{
${ }^{3}$ Implying that within PSCD bi- or multilateral cooperation between certain pMS cannot be vetoed by another pMS; only constructive abstention remains possible.
} 
get more bang out of such sums should not be too easily ignored. PSCD should be an attractive forum for those able and willing to join when it is launched as well for those that might join later. Those opting out will not suffer direct political disadvantages - but they will miss out on the very real benefits that PSCD will bring. Hence realistic but real criteria: achievable by every Member State that wants to, yet a binding commitment to do more than today; open to entry by all, but ensuring growing solidarity and increasingly ambitious commitments as the process continues.

Coordination. While preserving flexibility and bottom-up initiative, coordination through the permanent Capability Generation Conference should generate concrete projects to address all shortfalls needed to fulfil the Headline Goal 2010. This has proved impossible through an exclusively bottom-up approach, which has achieved some remarkable results but which has also reached its limits. Without collective top-down steering, significant progress is beyond reach. Simultaneously, the Capability Generation Conference will allow those that seek cooperation to find suitable partners, including for deepening existing multinational units or setting up new ones. This is not to pull all multinational military units and structures into PSCD nor even to have some of them managed by PSCD, but to stimulate pMS to use the full potential of such multinational formations, and to use them as frameworks for common deployment - in this regard as well cost-effectiveness will improve.

Cost-effectiveness. The criterion will gently oblige pMS to explore the full potential of four important cost-cutters: (1) collaborative armaments projects (from cradle to grave); (2) pooling; (3) role specialisation; (4) and perhaps most importantly, doing away with redundancies, for Europe does not need 1.8 million uniforms and the combined cost of all redundant assets and structures by far exceeds what is required to address the strategic shortfalls. These cost-cutters will produce a budgetary margin which, if pMS live up to the 
commitment not to lower their defence expenditures (as per criterion 2), will stay within the defence budget. The other criteria will ensure this margin will be spent on deployable and effectively deployed capabilities.

Assessment. pMS will of course decide, but the assessment role given by the Treaty to the EDA will ensure that for the first time their performance will be evaluated by a neutral body. Simultaneously, the Capability Generation Conference will engender an informal peer review process of investment plans. Unlike ESDP, CSDP should be more than a catalogue of paper commitments.

Significant military contributions. The permanent dialogue on defence planning will allow each and every pMS to opt for the development of specific military capabilities that would allow it to participate with significant military contributions in all of the potential Petersberg Tasks. That requires each to focus on his own centres of competence, to acquire or further develop those military forces and capabilities proven to be scarce during Force Generation Conferences, and to abandon capabilities proven to redundant. This will considerably enhance political solidarity among all Member States and will strengthen the Union as such, at no additional financial cost.

Boots on the ground. And what ultimately counts most: Europeans will have available and effectively deploy more troops for operations, be it under EU, NATO or UN command or in another multilateral configuration. In doing so they will finally live up to the expectations generated by the European Security Strategy and the Lisbon Treaty.

These are half a dozen good reasons why Member States should launch PSCD and mark the occasion by a declaration of the European Council. The Heads of State and 
Government can provide the high-level political impetus that will stimulate Foreign and Defence Ministers to take permanent and structured action. 


\section{Bruges Political Research Papers / Cahiers de recherche politique de Bruges}

No $14 / 2010$

Antonio Missiroli, Implementing the Lisbon Treaty: The External Policy Dimension

No 13/2010

Anne-Céline Didier, The European Institute of Innovation and Technology (EIT): A New Way for Promoting Innovation in Europe?

No 12/2010

Marion Salines, Success Factors of Macro-Regional Cooperation: The Example of the Baltic Sea Region

No $11 / 2010$

Martin Caudron, Galileo: Le Partenariat Public-Privé à l'Epreuve du « Juste Retour»

No 10/2009

Davide Bradanini, The Rise of the competitiveness Discourse-A Neo-Gramscian Analysis

No 9/ 2009

Adina Crisan, La Russie dans le nouveau Grand Jeu énergétique en Mer Noire: Nabucco et South Stream ou «l'art du kuzushi »

No 8 / 2008

Jonas Dreger, The Influence of Environmental NGOs on the Design of the Emissions Trading Scheme of the EU: An Application of the Advocacy Coalition Framework

No 7 / 2008

Thomas Kostera, Europeanizing Healthcare: Cross-border Patient Mobility and Its Consequences for the German and Danish Healthcare Systems

$06 / 2007$

Mathieu Rousselin, Le Multilatéralisme en Question : Le Programme de Doha pour le Développement et la Crise du Système Commercial Multilatéral

$05 / 2007$

Filip Engel, Analyzing Policy Learning in European Union Policy Formulation: The Advocacy Coalition Framework Meets New-Institutional Theory

$04 / 2007$ 
Michele Chang, Eric De Souza, Sieglinde Gstöhl, and Dominik Hanf, Papers prepared for the Colloquium, "Working for Europe: Perspectives on the EU 50 Years after the Treaties of Rome"

$03 / 2007$

Erwin van Veen, The Valuable Tool of Sovereignty: Its Use in Situations of Competition and Interdependence

$02 / 2007$

Mark Pollack, Principal-Agent Analysis and International Delegation: Red Herrings, Theoretical Clarifications, and Empirical Disputes

$01 / 2006$

Christopher Reynolds, All Together Now? The Governance of Military Capability Reform in the ESDP 


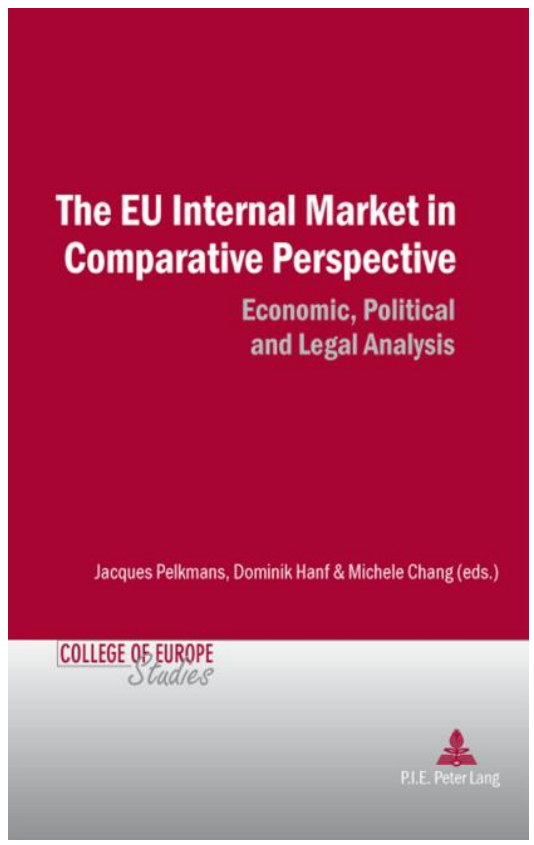

College of Europe Studies

Series Editors:

Govaere I. / Hanf D. / Mahncke D. / Pelkmans J.

Order online at www.peterlang.com

\section{PIE - Peter Lang Bruxelles}

Europe is in a constant state of flux. European politics, economics, law and indeed European societies are changing rapidly. The European Union itself is in a continuous situation of adaptation. New challenges and new requirements arise continually, both internally and externally.

The College of Europe Studies series seeks to publish research on these issues done at the College of Europe, both at its Bruges and its Natolin (Warsaw) campus. Focused on the European Union and the European integration process, this research may be specialised in the areas of political science, law or economics, but much of it is of an interdisciplinary nature. The objective is to promote understanding of the issues concerned and to make a contribution to ongoing discussions.

L'Europe subit des mutations permanentes. La vie politique, l'économie, le droit, mais également les sociétés européennes, changent rapidement. L'Union européenne s'inscrit dès lors dans un processus d'adaptation constant. Des défis et des nouvelles demandes surviennent sans cesse, provenant à la fois de l'intérieur et de l'extérieur.

La collection des Cahiers du Collège d'Europe publie les résultats des recherches menées sur ces thèmes au Collège d'Europe, au sein de ses deux campus (Bruges et Varsovie). Focalisés sur l'Union européenne et le processus d'intégration, ces travaux peuvent être spécialisés dans les domaines des sciences politiques, du droit ou de l'économie, mais ils sont le plus souvent 
de nature interdisciplinaire. La collection vise à approfondir la compréhension de ces questions complexes et contribue ainsi au débat européen.

Series Titles:

vol. 12 Men, Jong / Balducci, Giuseppe (eds.), Prospects and Challenges for EU-China Relations in the $21^{\text {st }}$ Century, 2010 (262 p.), ISBN 978-90-5201-641-2 pb.

vol. 11 Monar, Jörg (ed.), The Institutional Dimension of the European Union's Area of Freedom, Security and Justice, 2010 (268 p.), ISBN 978-90-5201-615-3 pb.

vol. 10 Hanf, Dominik / Malacek, Klaus / Muir, elise (eds.), Langues et construction européenne, 2010 (286 p.), ISBN 978-90-5201-594-1 pb.

vol. 9 Pelkmans, Jacques / Hanf, Dominik / Chang, Michele (eds.), The EU Internal Market in Comparative Perspective, 2008 (314 p.), ISBN 978-90-5201-424-1 pb.

vol. 8 Govaere, Inge / Ullrich, Hanns (eds.), Intellectual Property, Market Power and the Public Interest, 2008 (315 p.), ISBN 978-90-5201-422-7 pb.

vol. 7 Inotai, András, The European Union and Southeastern Europe: Troubled Waters Ahead?, 2007 (414 p.), ISBN 978-90-5201-071-7 pb.

vol. 6 Govaere, Inge / Ullrich, Hanns (eds.), Intellectual Property, Public Policy, and International Trade, 2007 (232 p.), ISBN 978-90-5201-064-9 pb.

vol. 5 Hanf, Dominik / Muñoz, Rodolphe (eds.), La libre circulation des personnes: États des lieux et perspectives, 2007 (329 p.), ISBN 978-90-5201-061-8 pb.

vol. 4 Mahncke, Dieter / Gstöhl, Sieglinde (eds.), Europe's Near Abroad: Promises and Prospects of the EU's Neighbourhood Policy, 2008 (316 p.), ISBN 978-90-5201-047-2.

vol. 3 Mahncke, Dieter / Monar, Jörg (eds.), International Terrorism: A European Response to a Global Threat?, 2006 (191p.), ISBN 978-90-5201-046-5 / US-ISBN 978-0-8204-6691-0 $\mathrm{pb}$.

vol. 2 Demaret, Paul / Govaere, Inge / Hanf, Dominik (eds.), European Legal Dynamics Dynamiques juridiques européennes, Revised and updated edition of 30 Years of European Legal Studies at the College ofEurope, 2005 / 2007 (571 p.), ISBN 978-90-5201-067-0 pb.

vol. 1 Mahncke, Dieter / Ambos, Alicia / Reynolds, Christopher (eds.), European Foreign Policy: From Rhetoric to Reality?, 2004 / second printing 2006 (381 p.), ISBN 978-90-5201247-6 / US-ISBN 978-0-8204-6627-9 pb. 
If you would like to be added to the mailing list and be informed of new publications and department events, please email rina.balbaert@ coleurope.eu. Or find us on Facebook College of Europe Politics and Administration Department. 